\title{
Therapeutic implication of HER2 in advanced biliary tract cancer
}

\author{
Ah-Rong Nam ${ }^{1, *}$, Ji-Won Kim ${ }^{2, *}$, Yongjun Cha ${ }^{1,3}$, Hyerim Ha ${ }^{3}$, Ji Eun Park ${ }^{1}$, Ju-Hee \\ Bang $^{1}$, Mei Hua Jin ${ }^{1}$, Kyung-Hun Lee ${ }^{1,3}$, Tae-Yong Kim ${ }^{1}$, Sae-Won Han ${ }^{1,3}$, Seock-Ah \\ Im $^{1,3}$, Tae-You Kim ${ }^{1,3}$, Do-Youn Oh ${ }^{1,3}$, Yung-Jue Bang ${ }^{1,3}$ \\ ${ }^{1}$ Cancer Research Institute, Seoul National University College of Medicine, Seoul, Korea \\ ${ }^{2}$ Department of Internal Medicine, Seoul National University Bundang Hospital, Seongnam, Korea \\ ${ }^{3}$ Department of Internal Medicine, Seoul National University Hospital, Seoul, Korea \\ *These authors contributed equally to this work \\ Correspondence to: Do-Youn Oh, email: ohdoyoun@snu.ac.kr
}

Keywords: HER2, biliary tract cancer, gallbladder cancer, trastuzumab, targeted therapy

Received: February 18, 2016

Accepted: July 27, 2016

Published: August 09, 2016

\section{ABSTRACT}

Currently, there is no validated therapeutic target for biliary tract cancer (BTC). This study aimed to investigate the pre-clinical and clinical implication of HER2 as a therapeutic target in BTC. We established two novel HER2-amplified BTC cell lines, SNU-2670 and SNU-2773, from gallbladder cancer patients. SNU-2670 and SNU-2773 cells were sensitive to trastuzumab, dacomitinib, and afatinib compared with nine HER2-negative BTC cell lines. Dacomitinib and afatinib led to G1 cell cycle arrest in SNU-2773 cells and apoptosis in SNU-2670 cells. Furthermore, dacomitinib, afatinib, and trastuzumab showed synergistic cytotoxicity when combined with some cytotoxic drugs including gemcitabine, cisplatin, paclitaxel, and 5-fluorouracil. In a SNU-2670 mouse xenograft model, trastuzumab demonstrated a good anti-tumor effect as a monotherapy and in combination with gemcitabine increasing apoptosis. In our clinical data, $\mathbf{1 3 . 0 \%}$ of patients with advanced BTC were defined as HER2-positive. Of these, three patients completed HER2-targeted chemotherapy. Two of them demonstrated a partial response, and the other one showed stable disease for 18 weeks. In summary, these pre-clinical and clinical data suggest that HER2 could be a therapeutic target, and that a HER2-targeting strategy should be developed further in patients with HER2-positive advanced BTC.

\section{INTRODUCTION}

In recent years, development of targeted agents significantly improved the prognosis of advanced cancer patients. However, there is no validated target for biliary tract cancer (BTC) as yet, and prognosis of advanced BTC patients is still dismal [1,2]. Therefore, there is still huge unmet need for the development of novel therapeutic targets in advanced BTC.

HER2 overexpression or amplification is observed in approximately $10-16 \%$ of gallbladder cancer and $5-11 \%$ of extrahepatic bile duct cancer [3-5], although its biologic importance or clinical implication are not as well understood as in breast cancer and gastric cancer [6-8]. A previous study showed that constitutive expression of HER2 in gallbladder epithelium lead to the development of adenocarcinoma [9]. A cholangiocarcinoma cell line with high HER2 expression demonstrated enhanced invasiveness, motility, and proliferation compared with the other cell lines without HER 2 overexpression via AKT/p70S6K pathway activation [10]. Therefore, it might be speculated that HER2 overexpression is important in the pathogenesis and progression of a certain subtype of BTC, leading to a dismal prognosis in this subset of patients as also observed in those patients with breast cancer with HER2 overexpression [11]. In addition, in gallbladder cancer, genes in the ErbB signaling pathways were more frequently mutated compared with other BTCs [12]. Therefore, it is suggested that overexpression or amplification of HER2 could be a promising therapeutic target in patients with BTC. HER2targeted strategy has dramatically improved the clinical outcome of patients with breast and gastric cancer, and has already been incorporated into the standard clinical practice in these patients [6-8]. However, since not all genetic 
alterations in tumor tissues could be therapeutic targets, it is necessary to investigate the pre-clinical and clinical implication of HER2 overexpression or amplification as a therapeutic target in BTC.

On the basis of this background, we conducted pre-clinical and clinical studies to identify clinical implication of HER2 positivity and to provide evidence for HER2-targeted therapy in patients with advanced BTC.

\section{RESULTS}

\section{Expression levels of HER family proteins in BTC cell lines}

Two novel HER2-amplified human BTC cell lines, SNU-2670 and SNU-2773, were established from tumor tissues from BTC patients. SNU-2670 cell line was established from the metastatic liver mass of a 51-year-old female Asian patient (patient A; Table 1) with gallbladder adenocarcinoma harboring a HER2 gene amplification with a HER2/CEP17 ratio of 5.76 by FISH and protein overexpression of $2+$ by IHC. SNU-2773 cell line was derived from a metastatic neck lymph node of a 50-year-old male Asian patient (patient B; Table 1) with gallbladder adenocarcinoma harboring a HER2 gene amplification with a HER2/CEP17 ratio of 2.67 by FISH and protein overexpression of $3+$ by IHC.

Among all 11 BTC cell lines, SNU-2670 and SNU-2773 expressed higher levels of total HER2 and phosphorylated HER2 compared with the other cell lines (Figure 1A). SNU-2670 and SNU-2773 cells harbored HER2 gene amplification as measured by FISH, while SNU-245, SNU-308, SNU-478, SNU-869, SNU-1179, and SNU-1196 cells did not (Supplementary Figure S1). SNU2670 cells expressed high levels of HER3 and SNU2773 cells expressed high levels of EGFR compared to the other cell lines.

\section{Cytotoxic effects of various agents in HER2-amplified BTC cells}

SNU-2670 cells were treated with various concentrations of targeted agents including trastuzumab, dacomitinib, and afatinib, and cytotoxic agents including gemcitabine, cisplatin, and 5-FU (Supplementary Table S1). Among targeted agents, dacomitinib and afatinib were the most sensitive drugs in SNU-2670 cells, with the half maximal inhibitory concentration $\left(\mathrm{IC}_{50}\right)$ values of $0.10 \mu \mathrm{M}$ and $0.13 \mu \mathrm{M}$, respectively. Both dacomitinib and afatinib also showed significant anti-proliferative effects in SNU-2773 cells with $\mathrm{IC}_{50}$ values of $1.5 \mu \mathrm{M}$ and $1.6 \mu \mathrm{M}$, respectively (Supplementary Table S2). SNU-2670 and SNU-2773 cell lines were more sensitive to trastuzumab compared with other BTC cell lines (Figure 1B). The antiproliferative effects of trastuzumab in these cells were comparable to those observed in HER2-positive gastric cancer cell lines, NCI-N87 and SNU-216, and a HER2positive breast cancer cell line, SK-BR-3 [13]. Colony formation assays also showed significant inhibition of proliferation of HER2-amplified BTC cells (Figure 1C). In colony formation assays, the $\mathrm{IC}_{50}$ values of dacomitinib and afatinib were $0.045 \mu \mathrm{M}$ and $0.010 \mu \mathrm{M}$ in SNU-2670 cells and $0.042 \mu \mathrm{M}$ and $0.019 \mu \mathrm{M}$ in SNU-2773 cells, respectively.

\section{Downstream signaling pathways of HER2 after HER2-targeted therapy}

Dacomitinib and afatinib decreased phosphorylation of EGFR and HER2 in SNU-2670 and SNU-2773 cells (Figure 1D). In addition, these targeted agents decreased phosphorylation of AKT, and ERK, two downstream molecules of EGFR and HER2. Trastuzumab abrogated phosphorylation of HER2 in SNU-2670 and SNU-2773 cells. In SNU-2670 cells, AKT and ERK phosphorylation was decreased by trastuzumab. In SNU-2773 cells, AKT phosphorylation was decreased by trastuzumab.

\section{Cell cycle arrest and apoptosis after HER2-targeted therapy}

Cell cycle analysis indicated that, in SNU2670 cells, dacomitinib and afatinib increased sub-G1 population, while G1 arrest was more predominant in SNU-2773 cells. Trastuzumab tended to increase G1 arrest (Figure 2A). Dacomitinib increased cleavage of PARP, caspase-3, and caspase-7, and afatinib increased cleavage of caspase-3 and caspase-7 in SNU-2670 cells (Figure 2B). In SNU-2773 cells, dacomitinib and afatinib decreased cyclin D/E/A expression, and trastuzumab decreased cyclin E/A expression (Figure 2C).

\section{Synergistic effects of HER2-targeted agents and cytotoxic agents}

SNU-2670 and SNU-2773 cells were simultaneously treated with cytotoxic agents, targeted agents, and combinations of cytotoxic drugs and targeted drugs using MTT assays and colony formation assays. A HER2targeted agent was administered in combination with a cytotoxic agent at a fixed ratio, which was decided on the basis of anti-proliferative effects of each drug (Figure 1B, Supplementary Tables S1 and S2). Dacomitinib or afatinib was combined with cisplatin, gemcitabine, paclitaxel, or 5-FU at a 1:10 ratio, and trastuzumab was combined with the cytotoxic agents at a $1(\mu \mathrm{g} / \mathrm{mL}): 1(\mu \mathrm{M})$ ratio. In both SNU-2670 and SNU-2773 cells, dacomitinib and afatinib produced synergistic cytotoxicity in combination with cisplatin (combination index $[\mathrm{CI}]=0.27$ and 0.61 for SNU-2670 cells, and 0.51 and 0.22 for SNU-2773 cells, respectively; Figure 3A). In addition, in SNU2670 cells, dacomitinib and afatinib showed synergistic 
Table 1: Characteristics of patients with HER2-positive BTC who completed trastuzumab-based chemotherapy

\begin{tabular}{|c|c|c|c|c|c|c|c|c|c|}
\hline Patients & Sex/Age & Primary site & Metastasis & HER2 IHC & HER2 FISH & HER2-directed therapy & $\begin{array}{c}\text { Best } \\
\text { response }\end{array}$ & $\begin{array}{c}\text { Duration } \\
\text { of response }\end{array}$ & OS \\
\hline A & $\mathrm{F} / 51$ & Gallbladder & Liver and lymph nodes & $2+$ & 5.76 & First-line: Trastuzumab + GP & SD & 18 weeks & 27 weeks \\
\hline B & $\mathrm{M} / 50$ & Gallbladder & Lung and lymph nodes & $3+$ & 2.67 & $\begin{array}{l}\text { Third-line: Trastuzumab + Paclitaxel } \\
\text { Fourth-line: Novel Anti-HER2 Antibody }\end{array}$ & $\begin{array}{l}\text { SD } \\
\text { PR }\end{array}$ & $\begin{array}{l}25 \text { weeks } \\
34 \text { weeks }\end{array}$ & $\begin{array}{l}\text { Alive at } \\
89 \text { weeks }\end{array}$ \\
\hline $\mathrm{C}$ & $\mathrm{F} / 63$ & Gallbladder & Lymph nodes & $3+$ & 9.53 & Third-line: Trastuzumab $+\mathrm{XP}$ & PR & 12 weeks & 79 weeks \\
\hline
\end{tabular}

Abbreviations: IHC, immunohistochemistry; FISH, fluorescent in situ hybridization; OS, overall survival; F, female; M, male; GP, gemcitabine/cisplatin; XP, capecitabine/cisplatin; $\mathrm{SD}$, stable disease; PR, partial response.

anti-proliferative effects when combined with 5-FU $(\mathrm{CI}=0.42$ and 0.15 , respectively). In SNU-2773 cells, dacomitinib synergized the anti-proliferative effects of paclitaxel $(\mathrm{CI}=0.62)$, and afatinib synergized both paclitaxel and 5-FU $(\mathrm{CI}=0.09$ and 0.05 , respectively). Trastuzumab also showed synergistic cytotoxic effects when combined with either gemcitabine or cisplatin in the two cell lines $(\mathrm{CI}=0.76$ and 0.19 for SNU-2670 cells, and 0.44 and 0.49 for SNU-2773 cells, respectively). In SNU-2670 cells, trastuzumab combined with 5-FU resulted in synergistic anti-proliferative effect $(\mathrm{CI}=0.27)$. In SNU-2773 cells, trastuzumab plus paclitaxel demonstrated synergism $(C I=0.12)$. The same findings were reproduced in colony formation assays (Figure 3B and Supplementary Figure S2): combination of a targeted agent and a cytotoxic agent demonstrated significantly decreased cell proliferation than treatment with a targeted agent alone. In western blot analysis, dacomitinib or afatinib combined with cisplatin abrogated phosphorylation of HER2 and its downstream molecules, AKT and ERK (Figure 3C). In SNU-2670 cells, dacomitinib or afatinib combined with gemcitabine decreased ERK phosphorylation. In SNU-2773 cells, dacomitinib and gemcitabine abrogated phosphorylation of HER2, AKT, and ERK. Trastuzumab in combination with cisplatin or gemcitabine decreased HER2 phosphorylation. Downregulation of AKT and ERK was also observed in cells treated with trastuzumab plus cisplatin or gemcitabine.

\section{Anti-tumor effects of trastuzumab alone or in combination with gemcitabine in xenograft model}

We confirmed the in vivo efficacy of trastuzumab alone, gemcitabine alone, or a combination of the two drugs in a SNU-2670 xenograft model. Trastuzumab alone showed significant antitumor activity, and the combination of trastuzumab and gemcitabine significantly enhanced antitumor activity $(P=0.020)$ (Figure 4A). In addition, combination treatment did not influence the body weight of mice (Figure 4B). Tumors treated with trastuzumab alone or gemcitabine alone exhibited a significant decrease in cell proliferation by Ki-67 assays and a significant increase in apoptosis by terminal deoxynucleotidyl transferase-mediated dUTP nick end labeling (TUNEL) assays. When the tumors were treated with a combination of trastuzumab and gemcitabine, cell proliferation was further decreased and apoptosis was further increased (Figure 4C). Western blot analysis demonstrated that trastuzumab or gemcitabine alone increased cleavage of caspase-7 (Figure 4D). The combination of trastuzumab and gemcitabine markedly decreased HER2 phosphorylation and increased cleavage of caspase- 7 .

\section{Clinical implication of HER2-positivity in advanced BTC patients}

Between July 2013 and July 2015, a total of 46 patients were enrolled. The baseline characteristics are listed in Table 2.

Five of 46 patients (10.9\%) were HER2 3+ by IHC: all had gallbladder cancer. Among eight patients with HER2 IHC 2+, HER2 FISH was performed in six patients and one (16.7\%) was defined as FISH-positive: this patient also had gallbladder cancer. In summary, a total of six patients $(13.0 \%)$ were defined as HER2-positive in our study cohort. In patients with gallbladder cancer $(N=21)$, the proportion of HER2-positive disease was $28.6 \%$.

During a median follow-up of 17.6 months (range, 1.7-33.0 months), 37 patients (80.4\%) experienced disease progression and 25 patients $(54.3 \%)$ died. In this cohort, 45 patients $(97.8 \%)$ received palliative chemotherapy. Treatment response to first-line chemotherapy was evaluated in 42 patients $(91.3 \%)$. The response rate (RR) was $8.7 \%(N=4)$. The median progression-free survival (PFS) for first-line chemotherapy was 4.7 months (95\% confidence interval, 2.2-7.2 months). The median overall survival (OS) was 16.6 months $(95 \%$ confidence interval, 9.9-23.3 months). PFS were not significantly different according to HER2 status $(P=0.747)$. Patients with HER2-positive disease tended to have longer OS numerically compared with those with HER2-negative disease without statistical significance (median OS, 20.6 months vs. 13.8 months; $P=0.430$; Figure 5A).

\section{Clinical efficacy of HER2-targeted therapy in HER2-positive BTC patients}

In the aforementioned cohort $(N=46)$, a total of four patients $(8.7 \%)$ received HER2-targeted chemotherapy. Among them, three patients completed the treatment at the 

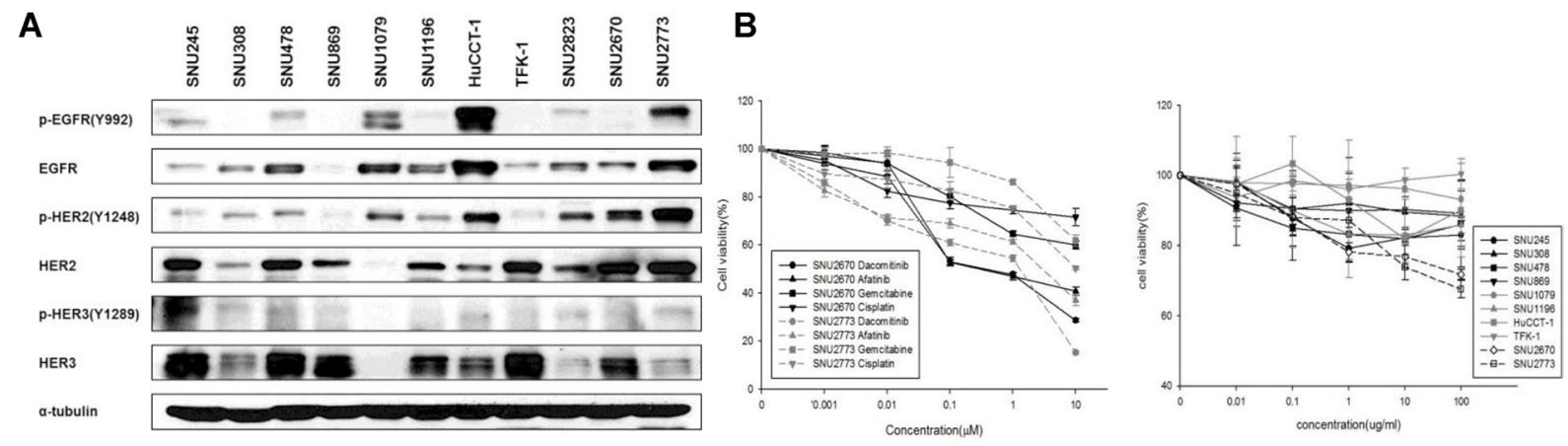

C
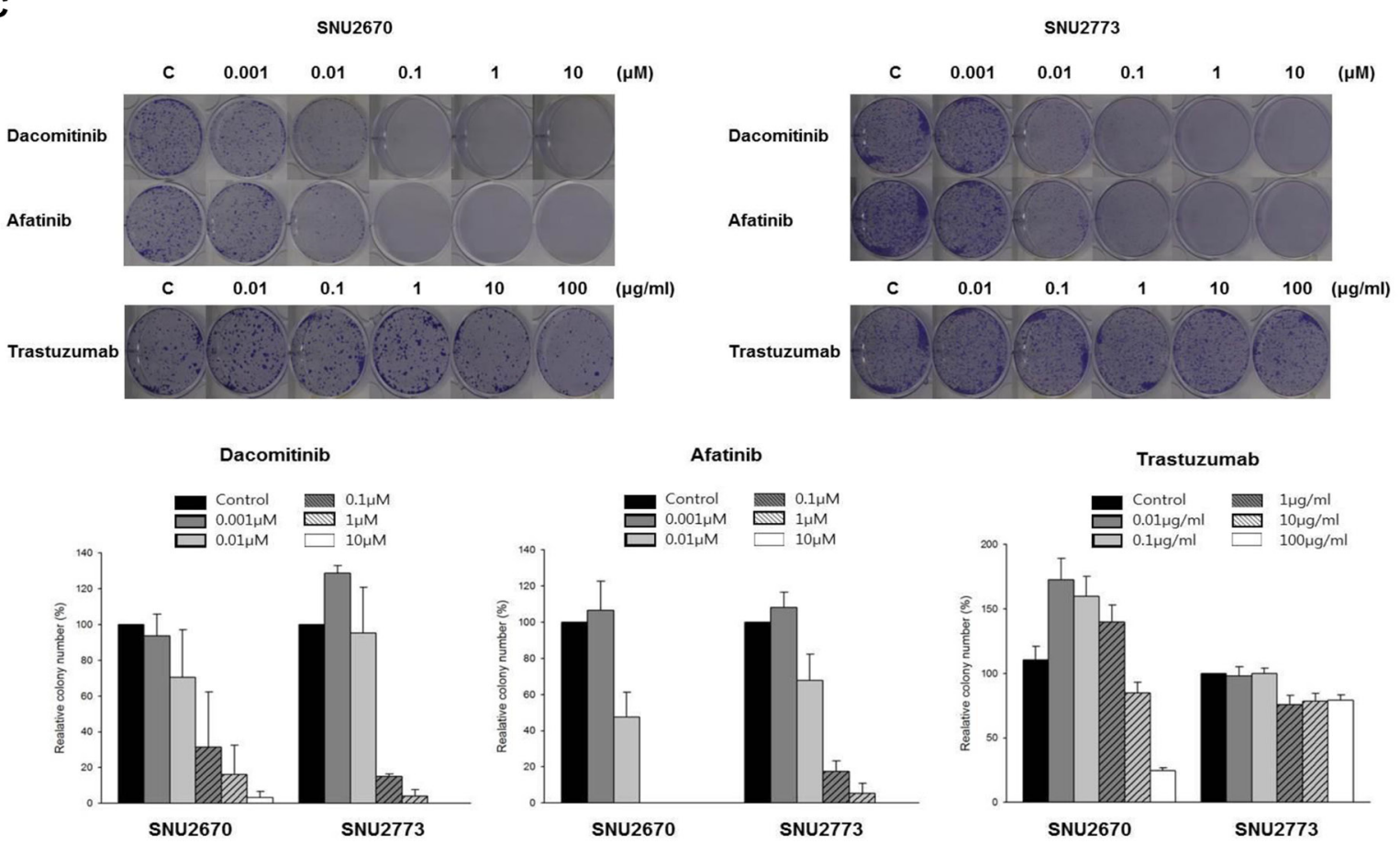

D
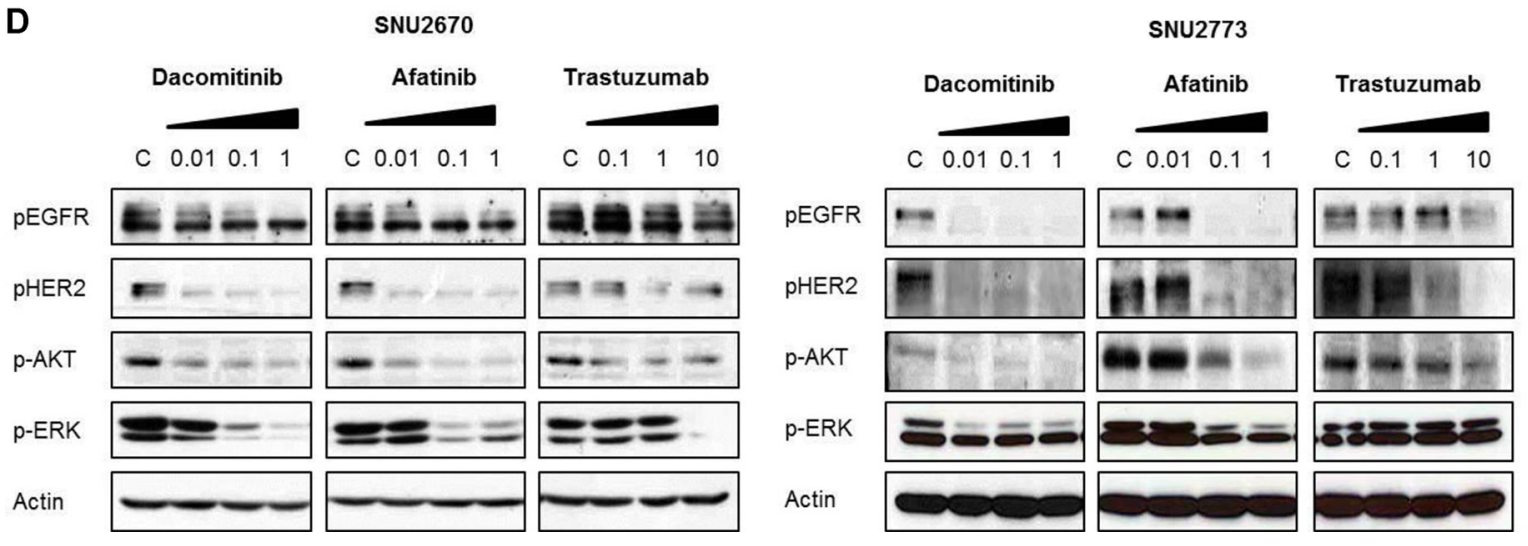

Figure 1: HER2-targeted treatment in HER2-amplified BTC cells. (A) Both SNU-2670 and SNU-2773 cell lines showed strong HER2 expression compared with the other cell lines. (B) Using MTT assays, anti-proliferative effects of dacomitinib, afatinib, gemcitabine, and cisplatin were evaluated in SNU-2670 and SNU-2773 cells. Anti-proliferative effects of trastuzumab were evaluated in 10 human BTC cell lines: SNU-245, SNU-308, SNU-478, SNU-869, SNU-1079, SNU-1196, SNU-2670, SNU-2773, HuCCT1, and TFK-1. (C) Colony formation assays demonstrated the cytotoxic effect of dacomitinib, afatinib, and trastuzumab. (D) HER2-targeted agents abrogated downstream signaling pathways of HER2. The cells were treated with dacomitinib $(0.01,0.1$, and $1 \mu \mathrm{M})$, afatinib $(0.01,0.1$, and $1 \mu \mathrm{M})$, and trastuzumab $(0.1,1$, and $10 \mu \mathrm{g} / \mathrm{mL})$ for $48 \mathrm{~h}$, and then immunoblotted with the indicated antibodies. 
A SNU2670
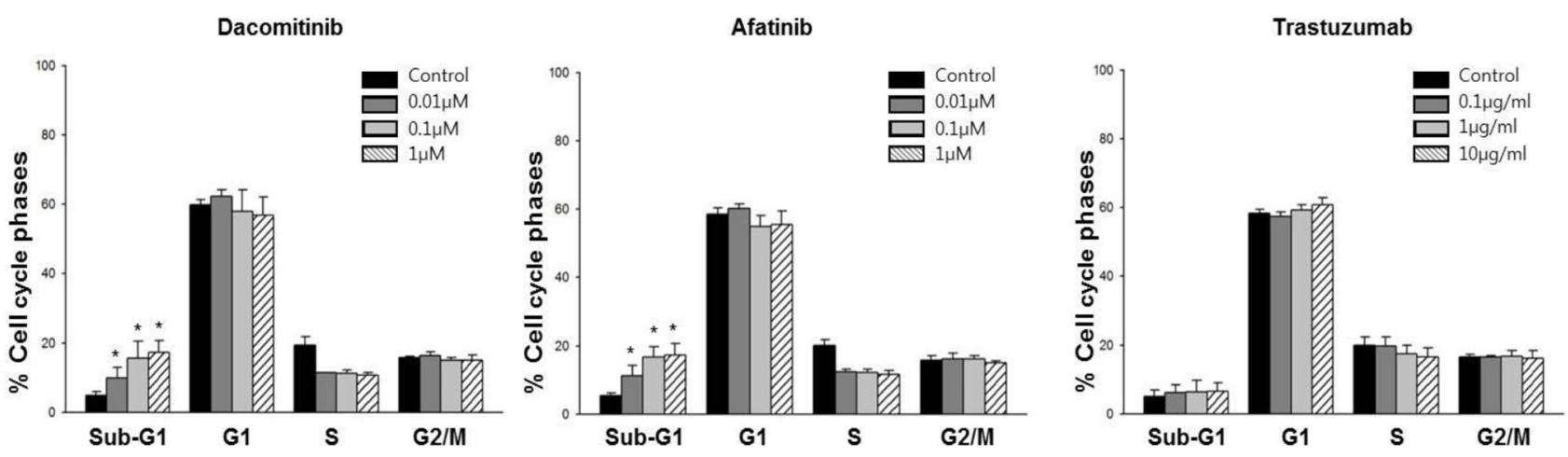

SNU2773
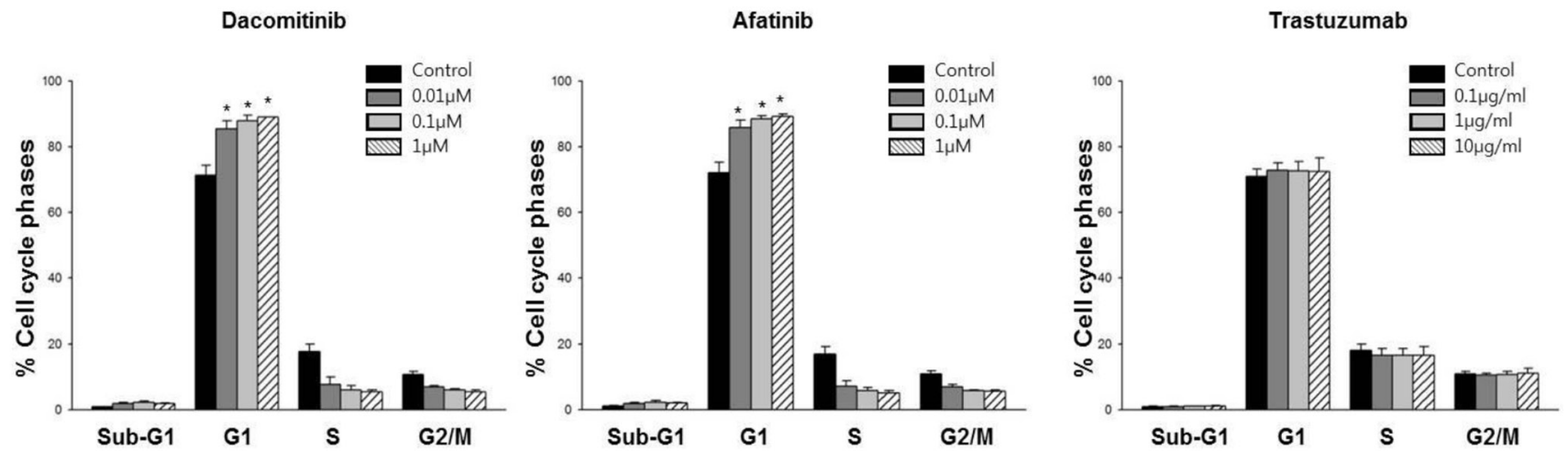

B

SNU2670

C

SNU2773
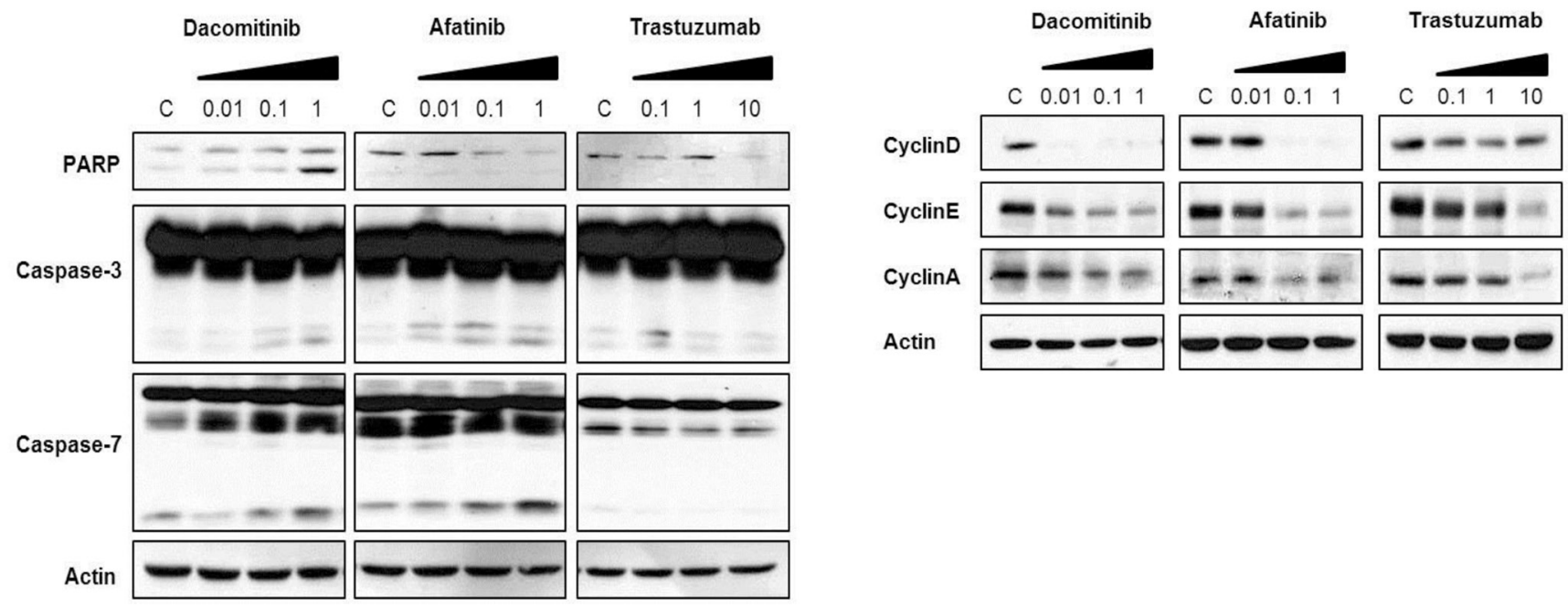

Figure 2: Cell cycle arrest and apoptosis after HER2-targeted therapy. (A) Cell cycle analysis was performed in SNU-2670 and SNU-2773 cells after dacomitinib, afatinib, and trastuzumab treatment. $* P<0.05$. (B) Effects of dacomitinib $(0,0.01,0.1$, and $1 \mu \mathrm{M})$, afatinib $(0,0.01,0.1$, and $1 \mu \mathrm{M})$, and trastuzumab $(0,0.1,1$, and $10 \mu \mathrm{g} / \mathrm{mL})$ on apoptosis pathways were evaluated in SNU-2670 cells. (C) Effects of dacomitinib $(0,0.01,0.1$, and $1 \mu \mathrm{M})$, afatinib $(0,0.01,0.1$, and $1 \mu \mathrm{M})$, and trastuzumab $(0,0.1,1$, and $10 \mu \mathrm{g} / \mathrm{mL})$ on $\mathrm{G} 1 \mathrm{cell}$ cycle arrest were evaluated in SNU-2773 cells. 
A
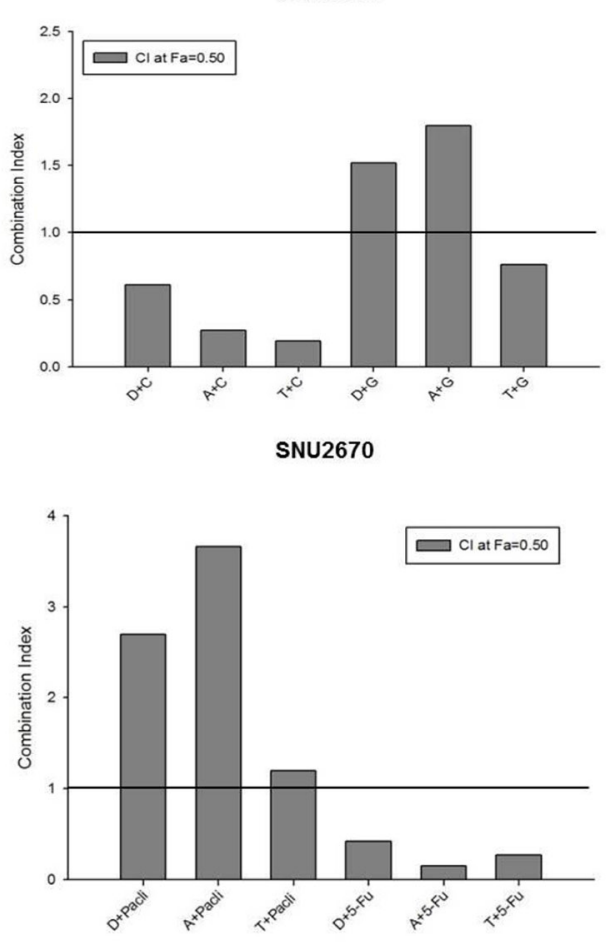

B
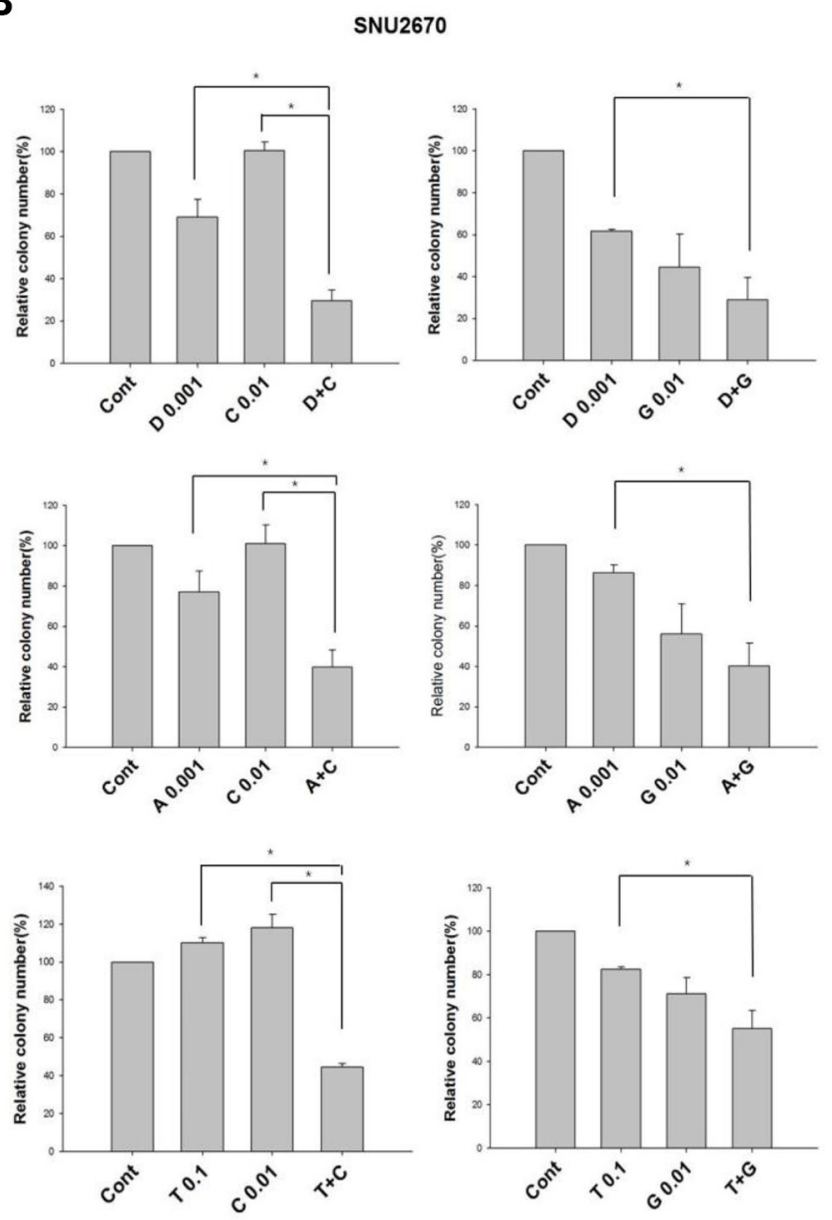
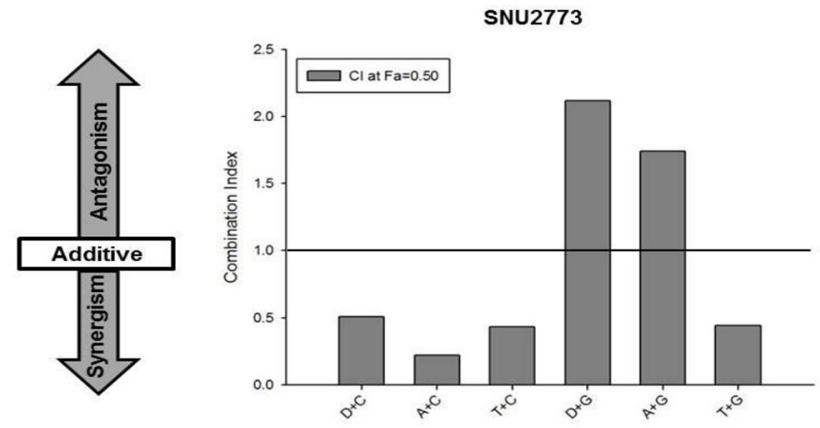

SNU2773
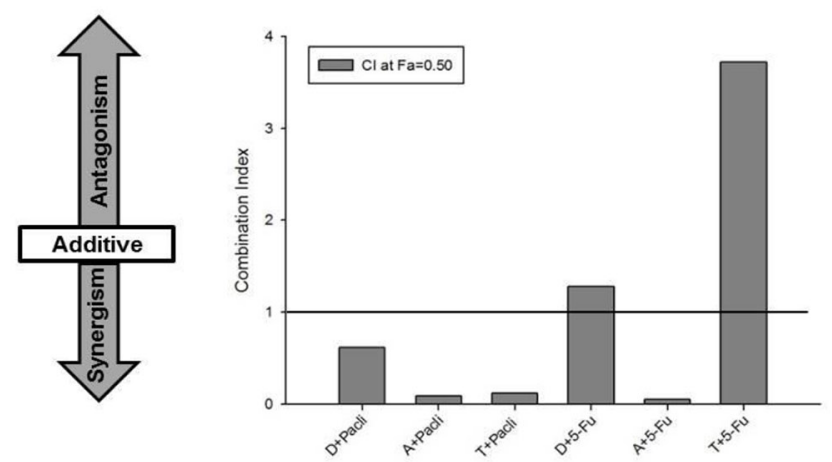

SNU2773
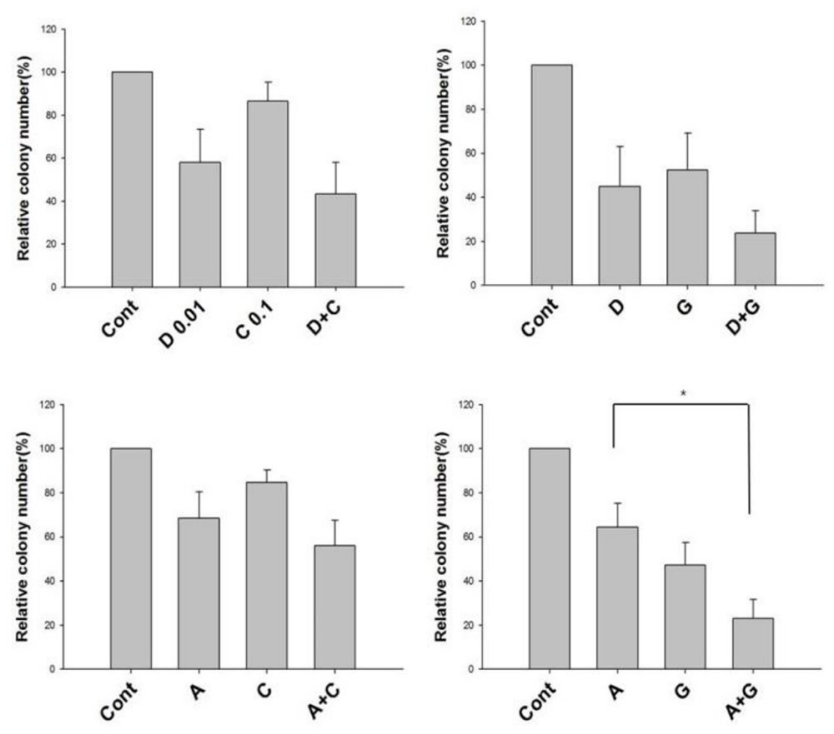
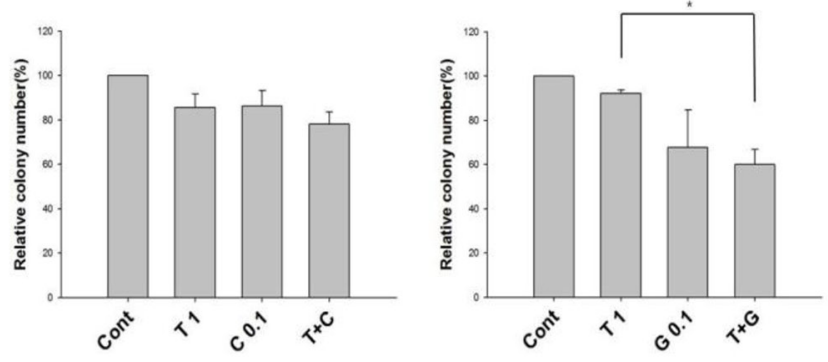


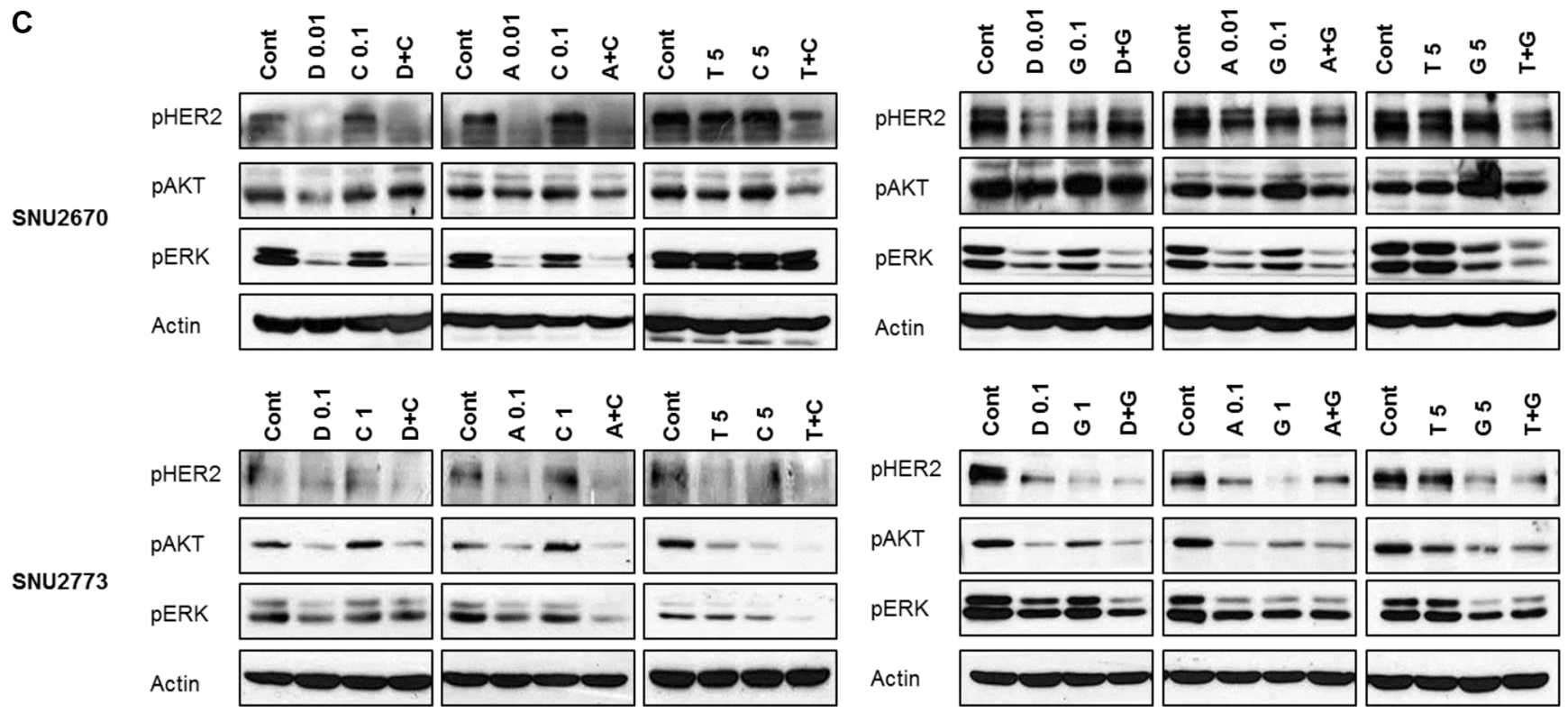

Figure 3: Synergistic cytotoxic effects of HER2-targeted agents and cytotoxic agents. (A) Anti-proliferative effects of combination chemotherapy of HER2-targeted agents including dacomitinib ('D'), afatinib ('A'), or trastuzumab ('T') and a cytotoxic agent including cisplatin ('C'), gemcitabine ('G'), paclitaxel ('P'), or 5-FU ('F') were evaluated in SNU-2670 and SNU-2773 cells using MTT assays. (B) Colony forming assays were performed to demonstrate the combined effect of a HER2-targeted agent and a cytotoxic agent. The concentration of each drug is indicated in the graph. The unit of concentration for each drug is $\mu \mathrm{M}$ for dacomitinib, afatinib, cisplatin, and gemcitabine and $\mu \mathrm{g} / \mathrm{mL}$ for trastuzumab. The concentration of each agent in combination treatment was the same as that in single treatment. Anti-proliferative effects of combination chemotherapy were statistically compared with those of single agent chemotherapy to evaluate the efficacy of combination therapy. ${ }^{*} P<0.05$. (C) Western blot analysis indicated that combination treatment more potently abrogated the downstream signaling pathways of HER2.

time of analysis. The baseline characteristics and treatment details of the three patients are summarized in Table 1.

Patient A was a 51-year-old female Asian who was diagnosed with gallbladder cancer with hepatic and lymph node metastasis. She received palliative firstline chemotherapy with trastuzumab combined with gemcitabine and cisplatin. The best response was stable disease (SD). A total of five cycles of gemcitabine and cisplatin were administered, along with three cycles of trastuzumab from cycles 3 to 5 . The duration of response was 18 weeks. The patient died 27 weeks after the start of first-line chemotherapy.

Patient B was a 50-year-old male Asian diagnosed with gallbladder cancer whose disease progressed to the lymph nodes and lung at 7 months after palliative resection and concurrent chemoradiation followed by chemotherapy with 5-FU and leucovorin. He had failed two lines of palliative chemotherapy including gemcitabine/cisplatin (PFS, 32 weeks) and 5-FU/leucovorin (PFS, 4 weeks). The patient was treated with third-line chemotherapy consisting of trastuzumab/paclitaxel. After two cycles of chemotherapy, CT scanning identified a cystic change in the metastatic lung nodules (Figure 5B). At baseline and after six cycles of chemotherapy, ${ }^{18} \mathrm{~F}$-fluorodeoxyglucose $\left({ }^{18} \mathrm{~F}-\mathrm{FDG}\right)$ PET revealed that the maximal standardized uptake values (SUVs) in the retroperitoneal lymph nodes (Figure 5C) and left supraclavicular lymph nodes decreased from 3.40 to 2.20 and from 1.93 to 1.70 , respectively. The best response was SD. The PFS for third-line chemotherapy was 25 weeks. After progression, the patient was enrolled in a phase I clinical trial of a novel anti-HER2-monoclonal antibody monotherapy. After two cycles, CT scanning identified a cystic change in the metastatic lung nodules (Figure 5D). After four cycles, ${ }^{18} \mathrm{~F}$-FDG PET scanning revealed further decreased metabolism in metastatic tumors in the lungs, $\mathrm{T} 1$ spine, left adrenal gland, and lymph nodes (Figure 5E). The best response was partial response (PR). The PFS for fourth-line chemotherapy was 34 weeks. Nevertheless, he remained alive at 89 weeks after third-line chemotherapy.

Patient $\mathrm{C}$ was a 63-year-old female Asian diagnosed with gallbladder cancer with lymph node metastasis, which harbored HER2 gene amplification with a HER2/ CEP17 ratio of 9.53 by FISH (Supplementary Figure S3) and was HER2 $3+$ by IHC. After palliative resection, she had failed two lines of palliative chemotherapy. Then, she received palliative third-line chemotherapy of trastuzumab combined with capecitabine and cisplatin. After two cycles, ${ }^{18} \mathrm{~F}-\mathrm{FDG}$ PET scanning demonstrated markedly decreased metabolism in the retroperitoneal lymph node metastasis with maximal SUV decrease from 13.98 to 7.3 (Figure 5F). In addition, CT scanning indicated that the size of the metastatic retroperitoneal lymph nodes decreased from $36.2 \mathrm{~mm} \times 21.7 \mathrm{~mm}$ to $29.1 \mathrm{~mm} \times 13.9 \mathrm{~mm}$. 
The best response was PR. The PFS was 12 weeks. The patient died 79 weeks after the start of first-line chemotherapy.

\section{DISCUSSION}

Available lines of evidence suggest that HER2 could be used for a novel therapeutic target in patients with BTC. However, preclinical evidence of HER2-directed therapy in HER2-amplified BTC cells has not yet been reported. In addition, only a few anecdotal cases have been published on the promising anti-tumor activity of trastuzumab-based combination chemotherapy in patients with HER2-positive BTC [14-16]. In this study, we successfully established two HER2-amplified BTC cell lines, SNU-2670 and SNU-2773, from patients with HER2-amplified BTC. In both in vitro and in vivo experiments using these cells, HER2-targeted agents such as dacomitinib, afatinib, and trastuzumab potently inhibited proliferation via abrogation of downstream signaling pathways of HER2, leading to G1 cell cycle arrest and apoptosis. In addition, we revealed that trastuzumab could be effectively combined with conventional cytotoxic agents including gemcitabine and cisplatin, which is currently the standard treatment option in patients with advanced BTC in the first-line setting [17]. In our patient cohort, three patients with HER2-positive BTC completed HER2-targeted chemotherapy, and clinical anti-tumor activity was observed in all of them:
A

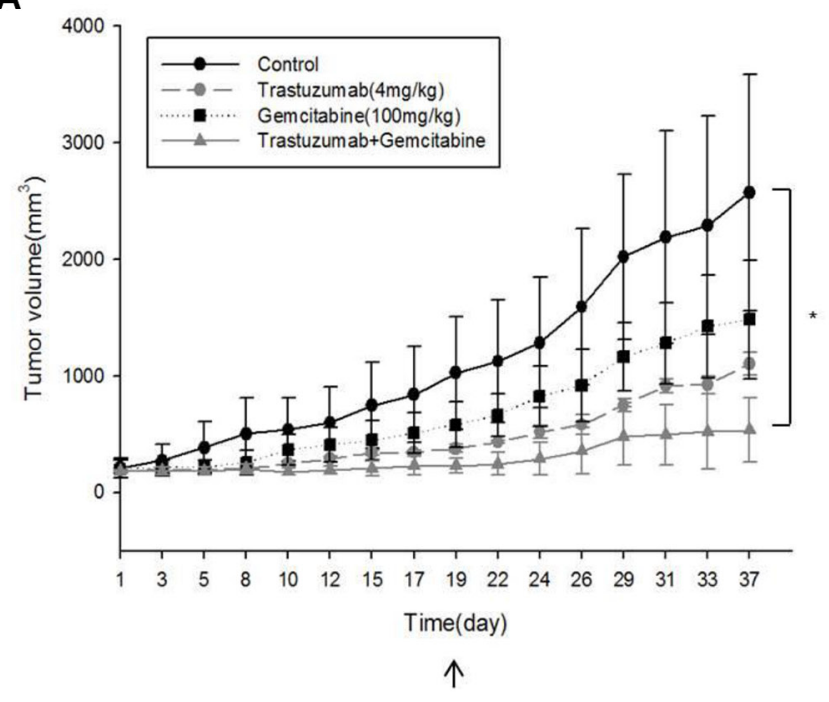

B

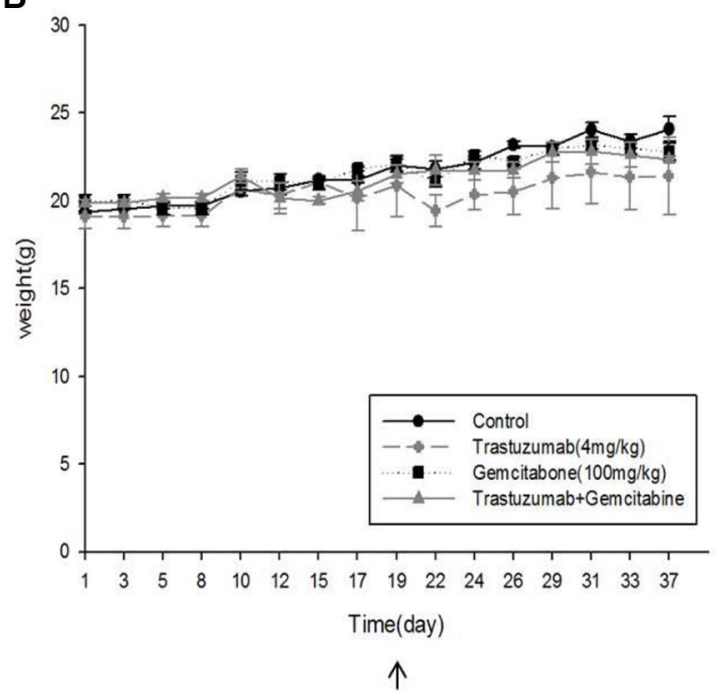

C

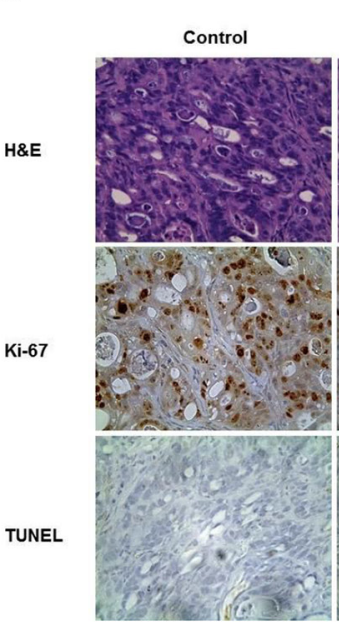

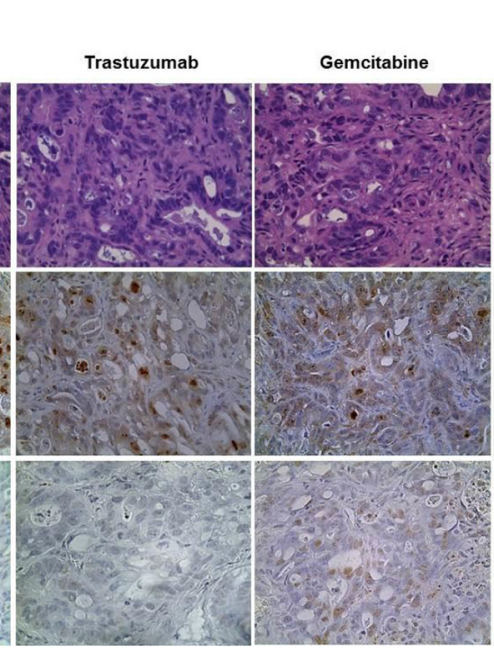

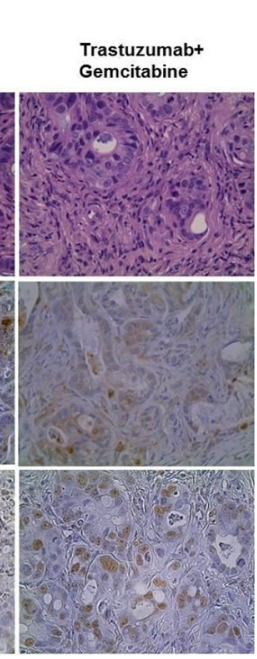

D

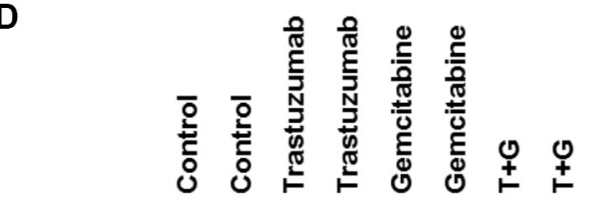

pHER2

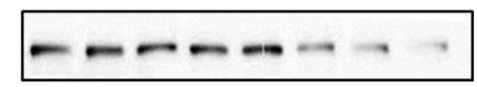

Caspase 3

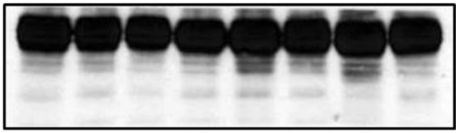

Caspase

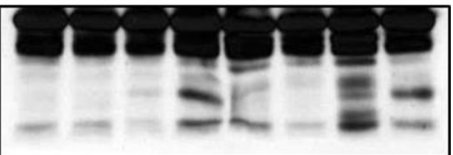

Actin

Figure 4: Synergistic anti-tumor effects of trastuzumab combined with gemcitabine in a mouse xenograft model. (A) In vivo efficacy of trastuzumab alone, gemcitabine alone, or a combination of the two drugs was evaluated using a SNU-2670 xenograft model. ${ }^{*} P<0.05$. (B) To evaluate the effect of chemotherapy on body weight, the body weight of mice was measured every other day. (C) At 37 days the tumors were harvested and analyzed using IHC. Ki-67 and TUNEL assays were performed to evaluate cell proliferation and apoptosis, respectively. (D) Western blot assays were performed using the excised tumors from the xenograft model to elucidate the effect of trastuzumab and/or gemcitabine on HER2 phosphorylation and apoptosis molecules. 
Table 2: Baseline characteristics of patients

\begin{tabular}{|c|c|c|}
\hline \multicolumn{2}{|c|}{ Characteristics $(N=46)$} & \multirow{2}{*}{$\frac{\text { Values }}{59(31-78)}$} \\
\hline Age - years & Median (range) & \\
\hline Sex - No. $(\%)$ & $\begin{array}{l}\text { Male } \\
\text { Female }\end{array}$ & $\begin{array}{l}25(54.3) \\
21(45.7)\end{array}$ \\
\hline Primary site - No. $(\%)$ & $\begin{array}{l}\text { Intrahepatic cholangiocarcinoma } \\
\text { Extrahepatic cholangiocarcinoma } \\
\text { Gallbladder cancer } \\
\text { Ampulla of Vater cancer }\end{array}$ & $\begin{array}{l}11(23.9) \\
11(23.9) \\
21(45.7) \\
3(6.5)\end{array}$ \\
\hline $\begin{array}{l}\text { Prior treatments before palliative first-line } \\
\text { chemotherapy - No. }(\%)\end{array}$ & $\begin{array}{l}\text { Curative surgery } \\
\text { Adjuvant chemoradiotherapy and/or chemotherapy } \\
\text { Palliative surgery } \\
\text { Palliative chemoradiotherapy and/or radiotherapy }\end{array}$ & $\begin{array}{l}15(32.6) \\
7(15.2) \\
13(28.3) \\
7(15.2)\end{array}$ \\
\hline No. of metastatic sites - No. (\%) & $\begin{array}{l}1 \\
2 \\
3 \\
\geq 4\end{array}$ & $\begin{array}{l}17(37.0) \\
16(34.8) \\
10(21.7) \\
3(6.5)\end{array}$ \\
\hline Sites of metastasis - No. (\%) & $\begin{array}{l}\text { Liver } \\
\text { Lymph node } \\
\text { Peritoneum } \\
\text { Lung } \\
\text { Bone } \\
\text { Others* }\end{array}$ & $\begin{array}{l}30(65.2) \\
29(63.0) \\
11(23.9) \\
10(21.7) \\
5(10.9) \\
3(6.5)\end{array}$ \\
\hline HER2 status - No. (\%) & $\begin{array}{l}\text { IHC } 3+ \\
\text { IHC } 2+\text { and FISH-positive } \\
\text { IHC } 2+\text { and FISH-negative } \\
\text { IHC } 2+\text { and FISH unknown } \\
\text { IHC } 1+ \\
\text { IHC-negative }\end{array}$ & $\begin{array}{l}5(10.9) \\
1(2.2) \\
5(10.9) \\
2(4.3) \\
12(26.1) \\
21(45.7)\end{array}$ \\
\hline ECOG performance status - No. (\%) & $\begin{array}{l}0 \text { or } 1 \\
2 \\
\text { Unknown }\end{array}$ & $\begin{array}{c}44(95.7) \\
1(2.2) \\
1(2.2)\end{array}$ \\
\hline First-line chemotherapy & $\begin{array}{l}\text { Gemcitabine }+ \text { Cisplatin } \\
\text { Others } \dagger\end{array}$ & $\begin{array}{c}40(87.0) \\
6(13.0)\end{array}$ \\
\hline
\end{tabular}

*Others include adrenal gland $(N=2)$ and pleura $(N=1)$.

$\dagger$ Others include trastuzumab + gemcitabine + cisplatin $(N=2)$, gemcitabine + oxaliplatin $(N=1)$, gemcitabine + carboplatin $(N=1)$, TS-1 single $(N=1)$, and no treatment $(N=1)$.

Abbreviations: HER2, human epidermal growth factor receptor 2; IHC, immunohistochemistry; FISH, fluorescent in situ hybridization; ECOG, Eastern Cooperative Oncology Group.

two patients demonstrated a partial response, and the other one showed stable disease for 18 weeks.

In our in vitro study, dacomitinib could nearly completely inhibit HER2 phosphorylation in both SNU-2670 and SNU-2773 cell lines. In addition, dacomitinib and afatinib could not potently inhibit EGFR phosphorylation in SNU-2670 cells compared with SNU2773 cells. Nevertheless, SNU-2670 cells were more sensitive to dacomitinib and afatinib than SNU-2773 cells: the $\mathrm{IC}_{50}$ values of SNU-2773 cells for dacomitinib and afatinib were higher more than 10 times compared with SNU-2670 cells. Because dacomitinib inhibits EGFR and HER4 as well as HER2, and afatinib inhibits EGFR as well as HER2, it is very difficult to estimate the amount of anti-proliferative effects of targeted agents merely on the basis of inhibitory effects of a single target molecule. Moreover, anti-proliferative effects of targeted agents were influenced by many factors such as target expression levels, mutational status, or protein stability of target molecules or down-stream molecules. Our results suggest that, in SNU-2670 cells, HER2 might be more important than EGFR when dacomitinib induced anti-proliferative effects, while both HER2 and EGFR were thought to be important in SNU-2773 cells. 
A

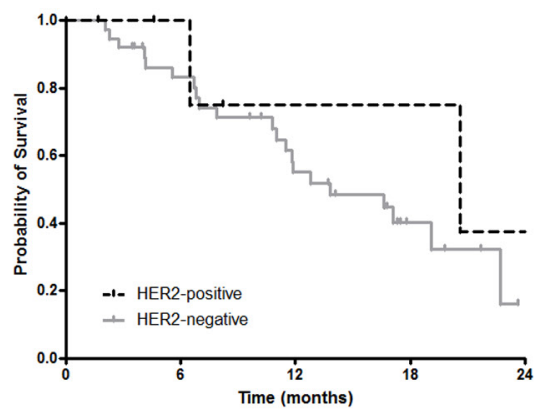

B

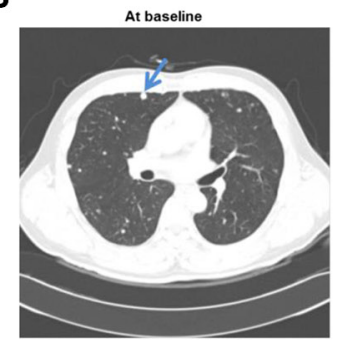

C

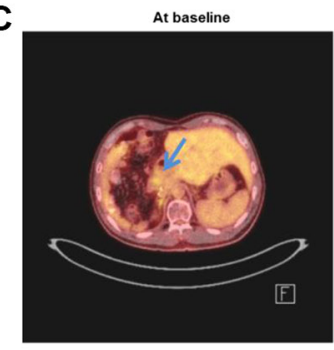

E

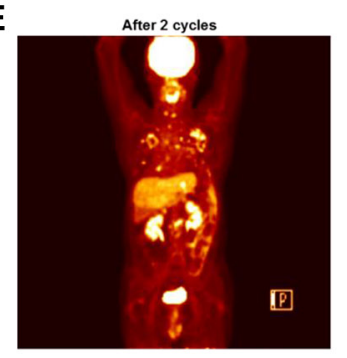

After 6 cycles
D
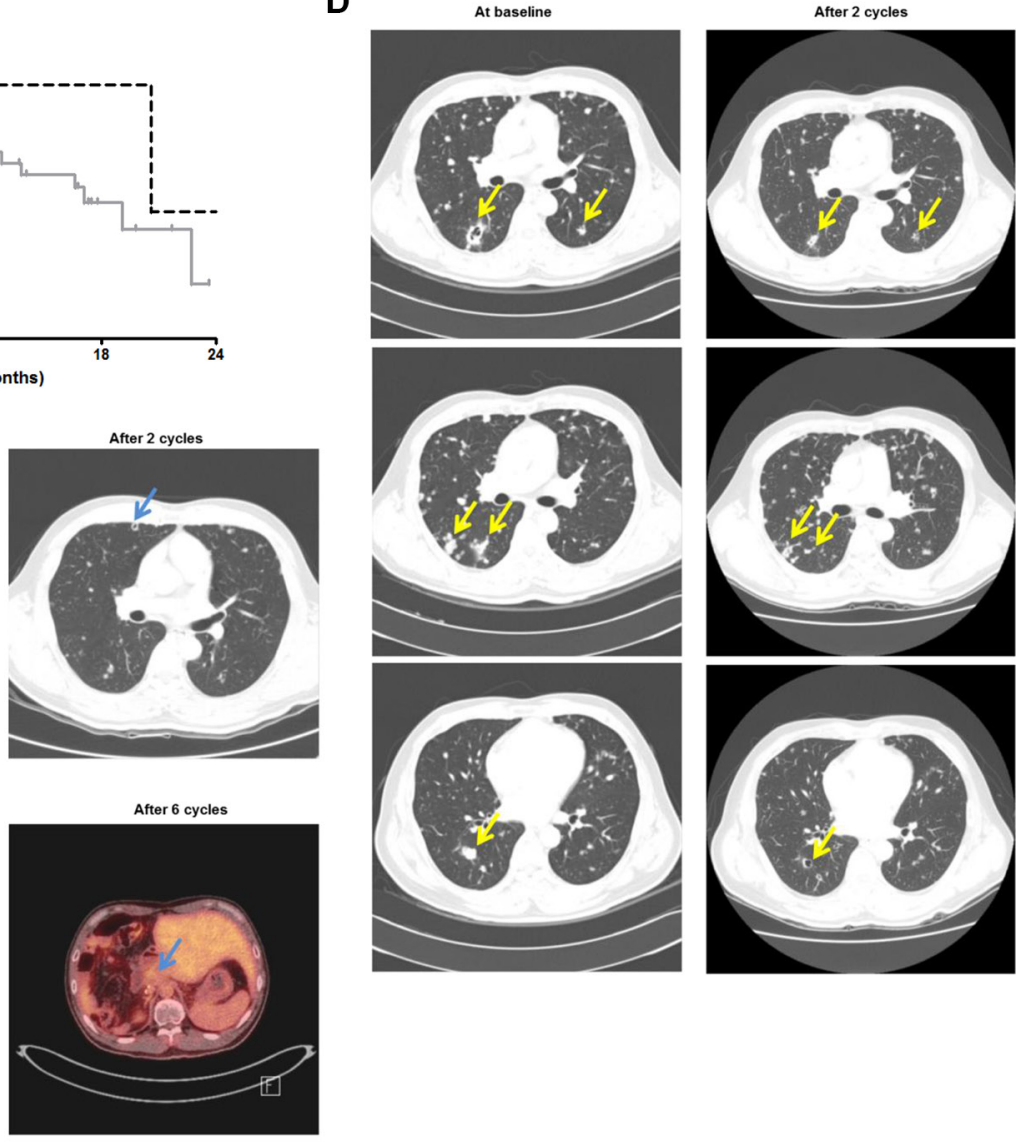

$\mathbf{F}$
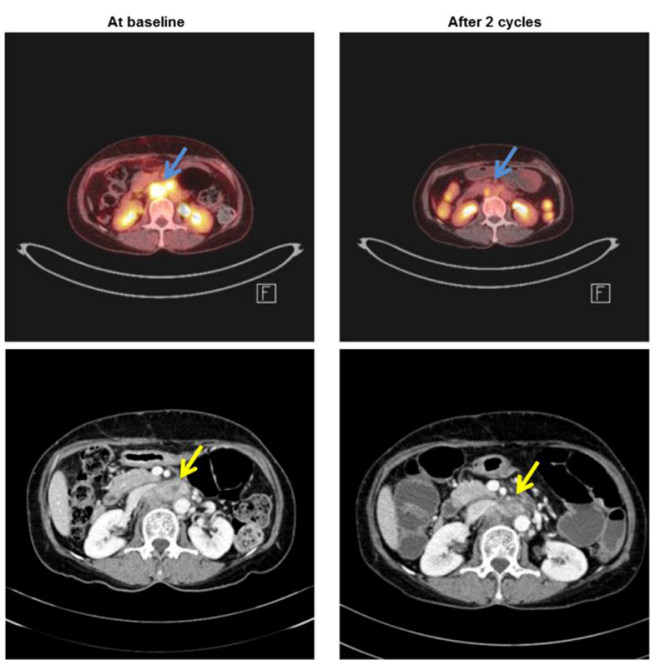

Figure 5: Clinical implications of HER2-targeted therapy in patients with advanced BTC. (A) In our patient cohort, patients with HER2-positive disease tended to live longer than those with HER2-negative disease (median OS, 20.6 months vs. 13.8 months; $P=0.430$ ). Two patients with HER2 IHC $2+$ and FISH unknown were excluded from the survival analysis. (B) In Patient B, after two cycles of third-line trastuzumab/paclitaxel chemotherapy, CT scanning revealed a cystic change in the metastatic lung nodules (arrows). (C) After six cycles, ${ }^{18} \mathrm{~F}$-fluorodeoxyglucose $\left({ }^{18} \mathrm{~F}-\mathrm{FDG}\right)$ positron emission tomography scans revealed decreased maximal standardized uptake values from 3.4 to 2.2 (arrows). (D) After progression, the patient was enrolled in a phase I clinical trial of a novel anti-HER2monoclonal antibody monotherapy as a fourth-line chemotherapy. After two cycles, CT scanning demonstrated a cystic change in the metastatic lung nodules (arrows). (E) After four cycles, ${ }^{18} \mathrm{~F}-\mathrm{FDG}$ PET scanning revealed further decreased metabolism in metastatic tumors in the lungs, T1 spine, left adrenal gland, and lymph nodes. (F) In Patient C, after two cycles of third-line chemotherapy of trastuzumab combined with capecitabine and cisplatin, ${ }^{18}$ F-FDG PET scanning demonstrated markedly decreased metabolism in the retroperitoneal lymph node metastasis (arrows) with maximal SUV decrease from 13.98 to 7.3. In addition, CT scanning indicated that the size of the metastatic retroperitoneal lymph nodes (arrows) decreased from $36.2 \mathrm{~mm} \times 21.7 \mathrm{~mm}$ to $29.1 \mathrm{~mm} \times 13.9 \mathrm{~mm}$. 
In our in vitro study data, the anti-proliferative effects of HER2-targeted agents in HER2-amplified BTC cells were comparable to those of previous studies using HER2-positive gastric or breast cancer cell lines. In both SNU-2670 and SNU-2773 cells, the $\mathrm{IC}_{50}$ values of dacomitinib and afatinib were similar to those of SNU-216 and NCI-N87 cells [18]. In addition, the anti-proliferative effects of trastuzumab in both SNU-2670 and SNU2773 cells were comparable to those observed in HER2positive gastric or breast cancer cells [13]. Therefore, it is suggested that the clinical efficacy of HER2-targeted therapy in patients with HER2-positive BTC could be substantial compared to those in patients with HER2positive gastric or breast cancer.

In our data, dacomitinib and afatinib appear to be more potent in terms of anti-proliferative effects than trastuzumab in vitro. In addition, trastuzumab plus cisplatin appear to be more synergistic than trastuzumab plus gemcitabine in SNU-2670 cells. Nevertheless, we performed in vivo experiments using trastuzumab plus gemcitabine combination using the SNU-2670 xenograft model. In the history of clinical development of HER2targeted agents, the starting point was trastuzumab, which was followed by other HER2-targeted agents such as lapatinib, trastuzumab emtansine (T-DM1), pertuzumab, etc. Although HER2-targeted small molecule inhibitors demonstrated excellent in vitro anti-proliferative activity $[13,19]$, these small molecule inhibitors could not demonstrated superiority over trastuzumab in terms of clinical efficacy so far [20, 21]. In addition, gemcitabine had long been used as a backbone to treat patients with advanced BTC, and recent studies showed that gemcitabine plus cisplatin is superior to gemcitabine alone $[17,22,23]$. Because cisplatin induces cumulative dosedependent toxicities such as nephropathy and neuropathy in clinical practice, it cannot be administered for a long time compared with gemcitabine in spite of clinical benefits. Therefore, we believe that gemcitabine plus trastuzumab might be the combination which could be exposed to patients with long-term tolerability.

Interestingly, in our study as well as previously published reports [14-16], all the responders to trastuzumab-based chemotherapy were gallbladder cancer patients. In previous studies, HER2 positivity of BTC differs according to its primary site: among BTCs, the proportion of HER2 3+ by IHC was highest in gallbladder cancer, followed by extrahepatic cholangiocarcinoma and intrahepatic cholangiocarcinoma $[4,5]$. In our study, all six patients with HER2-positive disease had gallbladder cancer. In addition, recent genomic studies identified that the mutational profiles of various BTCs were quite distinct according to their primary sites or causative etiologies [12, 24-26]. These results suggest that the pathogenesis of BTCs may be distinct according to these factors as well, and thus different treatment strategies may be applicable according to the clinical information and the results of genetic or molecular profiling. Therefore, to increase the efficacy of chemotherapy in BTC patients, further studies should focus on the identification of potential biomarkers for targeted therapy, to enable the selection and enrichment of patients who can benefit more from novel targeted agents.

The prognostic role of HER2 overexpression or amplification has not yet been thoroughly investigated in BTC. Some studies failed to demonstrate the prognostic impact of HER2 overexpression by IHC in patients with BTC, in part because of the relatively small sample size and heterogeneity of patient characteristics [27, 28], while the other reports showed that HER2 overexpression or amplification indicated worse prognosis of patients [29, 30]. The prognostic role of HER2 overexpression or amplification is still inconclusive in our study, possibly because of the effects of HER2-directed therapy in these patients.

In conclusion, our pre-clinical and clinical data suggest that HER2-directed therapy can be a promising treatment option in patients with HER2-positive advanced BTC and warrants further clinical trials in these patients. This study may provide a rationale for further investigations to clarify the efficacy and toxicity of trastuzumab-based combination chemotherapy in patients with HER2-positive advanced BTC.

\section{MATERIALS AND METHODS}

\section{Human BTC cell lines}

A total of 11 human BTC cell lines were used in this study. SNU-245, SNU-308, SNU-478, SNU-869, SNU1079, SNU-1196, and SNU-2823 cell lines were obtained from Korean Cell Line Bank, Seoul, Korea. HuCCT1 and TFK-1 cell lines were obtained from RIKEN BioResource Center, Ibaraki, Japan. HER2-amplified human BTC cell lines, SNU-2670 and SNU-2773, were established from tumor tissues from BTC patients using a previously described method [31].

All the cell lines were maintained in RPMI-1640 culture media supplemented with $10 \%$ fetal bovine serum (WELGENE Inc., Gyeongsan, Korea) and $10 \mu \mathrm{g} / \mathrm{mL}$ gentamicin in a humidified atmosphere containing 5\% $\mathrm{CO}_{2}$ at $37^{\circ} \mathrm{C}$.

\section{Tested agents}

Trastuzumab, a monoclonal antibody for HER2, was purchased from Genentech (South San Francisco, CA, USA). Dacomitinib (PF-00299804), an irreversible pan-HER inhibitor, and afatinib (BIBW-2992), a dual inhibitor of EGFR and HER2, were purchased from Selleck Chemicals LLC (Houston, TX, USA). Gemcitabine, cisplatin, and 5-fluorouracil (5-FU) were purchased from Lilly Korea Co., Seoul, Korea, JW Pharmaceutical Co., Seoul, Korea, and Ildong Pharmaceutical Co., Seoul, Korea, respectively. 


\section{Cell growth inhibition assays}

Cells were seeded at a density of 5,000 cells per well in 96-well plates and exposed to increasing concentrations of various targeted and cytotoxic agents for $72 \mathrm{~h}$. After drug treatment, the absorbance of MTT dye was measured at $540 \mathrm{~nm}$ with a VersaMax microplate reader (Molecular Devices, Sunnyvale, CA, USA).

For colony formation assays, the cells were seeded at a density of 3,000 cells per well in six-well plates and treated with targeted agents. After 12 days, the cell colonies were stained with $0.1 \%$ Coomassie Blue solution (Sigma-Aldrich, St. Louis, MO, USA), and counted using a Gel Doc (Bio-Rad, Hercules, CA, USA). The data presented are representative of three independent experiments.

\section{Western blot analysis}

Proteins were extracted and equal amount of proteins were separated on $10 \%$ sodium dodecyl sulfate polyacrylamide gels and transferred onto nitrocellulose membranes. The membranes were probed overnight at $4^{\circ} \mathrm{C}$ with appropriate primary antibodies. Primary antibodies against the following molecules were purchased from Cell Signaling Technology (Beverly, MA, USA): EGFR, phosphorylated EGFR (Tyr992), HER2, phosphorylated HER2 (Tyr1248), HER3, phosphorylated HER3 (Tyr1289), phosphorylated STAT3 (Tyr705), phosphorylated AKT (Ser473), phosphorylated ERK (Thr202/Tyr204), PARP, caspase-3, and caspase-7. Anti- $\alpha$-tubulin and anti- $\beta$-actin antibodies were purchased from Sigma-Aldrich (St. Louis). Anticyclin $\mathrm{A}$, anti-cyclin $\mathrm{D}$, and anti-cyclin $\mathrm{E}$ antibodies were purchased from Santa Cruz Biotechnology (Dallas, TX, USA). Antibody binding was detected using an enhanced chemiluminescence system according to the manufacturer's protocol (Amersham Biosciences; Piscataway, NJ, USA). Anti-mouse and rabbit secondary antibodies were purchased from Thermo Scientific Inc. (Waltham, MA, USA).

\section{Cell cycle analysis}

The cells treated with dacomitinib, afatinib, and trastuzumab at various concentrations for $48 \mathrm{~h}$ were harvested, fixed with cold 70\% ethanol, and then stored at $-20^{\circ} \mathrm{C}$ for at least $24 \mathrm{~h}$. The cells were washed in phosphate-buffered saline (PBS) and incubated with $20 \mathrm{mg} / \mathrm{mL}$ RNase A (Invitrogen, Carlsbad, CA, USA) at $37^{\circ} \mathrm{C}$ for $20 \mathrm{~min}$. Next, the cells were stained with $20 \mathrm{mg} / \mathrm{mL}$ propidium iodide (Sigma-Aldrich), and the DNA content of the cells $\left(1.0 \times 10^{4}\right.$ cells per experimental group) was quantified using a FACS Calibur flow cytometer (BD Biosciences, Franklin Lakes, NJ, USA).

\section{In vivo study}

Female Balb/c athymic nude mice aged 4-6 weeks were purchased from Central Lab Animal Inc., Seoul, Korea. The mice were injected subcutaneously in the right flank with $5 \times 10^{7} \mathrm{SNU}-2670$ cells in $100 \mu \mathrm{L}$ of PBS. After implantation of the tumor cells, the size of the resulting tumors was measured every other day using calipers; the body weight of each mouse was also determined every other day. The tumor volume was calculated using the following formula: (width ${ }^{2} \times$ height)/2. When the tumor volume reached 150 to $200 \mathrm{~mm}^{3}$, the mice were randomly divided into four groups: control, trastuzumab, gemcitabine, and trastuzumab plus gemcitabine. Trastuzumab $(4 \mathrm{mg} / \mathrm{kg})$ and $/$ or gemcitabine $(100 \mathrm{mg} / \mathrm{kg})$ was injected intraperitoneally twice a week for 3 weeks. At 37 days, the mice were euthanized with $\mathrm{CO}_{2}$. The tumors were excised and stored in liquid nitrogen until further analysis by IHC staining and western blot. The animal experiments were performed at the Biomedical Center for Animal Resource Development of Seoul National University, Seoul, Korea, according to the institutional guidelines.

\section{IHC of tumor tissues from xenograft model}

The histologic sections from individual paraffinembedded xenograft tumor tissues were deparaffinized and dehydrated. IHC detection of proliferating cells was conducted using anti-rabbit polyclonal antibody against Ki-67 (GeneTex, Inc., Irvine, CA, USA) at a dilution of 1:100. TUNEL assays were conducted for IHC detection of apoptosis using an ApopTag In situ Apoptosis Detection Kit (EMD Millipore, Billerica, MA, USA), in accordance with the manufacturer's protocol.

\section{Clinical materials}

After informed consent was obtained, patients with unresectable or recurrent BTC who planned to undergo palliative chemotherapy were enrolled in the prospective cohort study to collect biomaterials for translational research. Data regarding patient demographics, pathologic classification, treatment response, PFS, and OS were obtained from medical record review. Treatment response was evaluated using a multi-detector CT scan by Response Evaluation Criteria in Solid Tumors version 1.1 [32]. PFS was calculated from the initiation of palliative chemotherapy to documented disease progression or death from any cause. OS was calculated from the start of chemotherapy to death from any cause.

HER2 positivity was defined as an intensity of $3+$ by IHC or as a HER2/CEP17 (centromeric probe for chromosome 17) ratio of more than 2.0 by FISH, as previously described [4, 33-35]. 


\section{Statistics}

Experimental data were expressed as the mean \pm standard error (SE) and compared using Student's $t$-test. $\mathrm{IC}_{50}$ of chemotherapeutic agents was analyzed using SigmaPlot software (Systat Software, Inc., San Jose, CA, USA). The combined effects of various chemotherapeutic agents were analyzed by CalcuSyn software (Biosoft, Ferguson, MO, USA) using the Chou-Talalay method as previously described [36]. The CI values of $<1,1$ and $>1$ indicate synergism, an additive effect, and antagonism, respectively. The median PFS and OS were calculated using the Kaplan-Meier method. Comparison of survival data was performed using the log rank test. All statistical tests were two-sided, with significance defined as $P<0.05$. All analyses were performed using IBM SPSS version 22.0 (IBM, Armonk, NY, USA).

\section{Study approval}

The animal experiments were approved by the institutional animal care and use committee (IACUC) of Seoul National University. Signed informed consent was obtained from each patient before study entry. This study protocol was reviewed and approved by the institutional review board (IRB) of the Seoul National University Hospital (IRB registration No. 1306-069-497) and conducted in accordance with the precepts established by the Helsinki Declaration.

\section{ACKNOWLEDGMENTS}

We sincerely thank the patients who consented to participate in the study and provided biomaterials for cancer cell line establishment.

\section{CONFLICTS OF INTEREST}

The authors declare no conflicts of interest.

\section{GRANT SUPPORT}

This study was supported by a grant from the National R\&D Program for Cancer Control, Ministry of Health \& Welfare, Korea (http://www.mohw.go.kr/) (Grant No. 1320090) to Prof. Do-Youn Oh. The funder had no role in study design, data collection and analysis, decision to publish, or preparation of the manuscript.

\section{REFERENCES}

1. Pinter M, Hucke F, Zielonke N, Waldhor T, Trauner M, Peck-Radosavljevic M, Sieghart W. Incidence and mortality trends for biliary tract cancers in Austria. Liver Int. 2014; 34:1102-1108.
2. Yang JD, Kim B, Sanderson SO, Sauver JS, Yawn BP, Larson JJ, Therneau TM, Roberts LR, Gores GJ, Kim WR. Biliary tract cancers in Olmsted County, Minnesota, 1976-2008. Am J Gastroenterol. 2012; 107:1256-1262.

3. Ross JS, Wang K, Javle MM, Catenacci DV, Shroff RT, Ali SM, Elvin JA, Chmielecki J, Yelensky R, Lipson D, Miller VA, Stephens PJ, Meric-Bernstam F. Comprehensive genomic profiling of biliary tract cancers to reveal tumor-specific differences and frequency of clinically relevant genomic alterations. J Clin Oncol. 2015; 33:4009.

4. Yan M, Schwaederle M, Arguello D, Millis SZ, GatalicaZ, Kurzrock R. HER2 expression status in diverse cancers: review of results from 37,992 patients. Cancer Metastasis Rev. 2015; 34:157-164.

5. Nakazawa K, Dobashi Y, Suzuki S, Fujii H, Takeda Y, Ooi A. Amplification and overexpression of c-erbB-2, epidermal growth factor receptor, and c-met in biliary tract cancers. J Pathol. 2005; 206:356-365.

6. Marty M, Cognetti F, Maraninchi D, Snyder R, Mauriac L, Tubiana-Hulin M, Chan S, Grimes D, Anton A, Lluch A, Kennedy J, O'Byrne K, Conte P, et al. Randomized phase II trial of the efficacy and safety of trastuzumab combined with docetaxel in patients with human epidermal growth factor receptor 2-positive metastatic breast cancer administered as first-line treatment: the M77001 study group. J Clin Oncol. 2005; 23:4265-4274.

7. Piccart-Gebhart MJ, Procter M, Leyland-Jones B, Goldhirsch A, Untch M, Smith I, Gianni L, Baselga J, Bell R, Jackisch C, Cameron D, Dowsett M, Barrios CH, et al. Trastuzumab after adjuvant chemotherapy in HER2positive breast cancer. N Engl J Med. 2005; 353:1659-1672.

8. Bang YJ, Van Cutsem E, Feyereislova A, Chung HC, Shen L, Sawaki A, Lordick F, Ohtsu A, Omuro Y, Satoh T, Aprile G, Kulikov E, Hill J, et al. Trastuzumab in combination with chemotherapy versus chemotherapy alone for treatment of HER2-positive advanced gastric or gastrooesophageal junction cancer (ToGA): a phase 3, open-label, randomised controlled trial. Lancet. 2010; 376:687-697.

9. Kiguchi K, Carbajal S, Chan K, Beltran L, Ruffino L, Shen J, Matsumoto T, Yoshimi N, DiGiovanni J. Constitutive expression of ErbB-2 in gallbladder epithelium results in development of adenocarcinoma. Cancer Res. 2001; 61:6971-6976.

10. Treekitkarnmongkol W, Suthiphongchai T. High expression of ErbB2 contributes to cholangiocarcinoma cell invasion and proliferation through AKT/p70S6K. World J Gastroenterol. 2010; 16:4047-4054.

11. Ross JS, Fletcher JA. The HER-2/neu Oncogene in Breast Cancer: Prognostic Factor, Predictive Factor, and Target for Therapy. Oncologist. 1998; 3:237-252.

12. Li M, Zhang Z, Li X, Ye J, Wu X, Tan Z, Liu C, Shen B, Wang XA, Wu W, Zhou D, Zhang D, Wang T, et al. Whole-exome and targeted gene sequencing of gallbladder carcinoma identifies recurrent mutations in the ErbB pathway. Nat Genet. 2014; 46:872-876. 
13. Kim SY, Kim HP, Kim YJ, Oh do Y, Im SA, Lee D, Jong HS, Kim TY, Bang YJ. Trastuzumab inhibits the growth of human gastric cancer cell lines with HER2 amplification synergistically with cisplatin. Int J Oncol. 2008; 32:89-95.

14. Law LY. Dramatic response to trastuzumab and paclitaxel in a patient with human epidermal growth factor receptor 2-positive metastatic cholangiocarcinoma. J Clin Oncol. 2012; 30:e271-273.

15. Sorscher S. Marked radiographic response of a HER2-overexpressing biliary cancer to trastuzumab. Cancer Manag Res. 2013; 9:1-3.

16. Javle M, Churi C, Kang HC, Shroff R, Janku F, Surapaneni R, Zuo M, Barrera C, Alshamsi H, Krishnan S, Mishra L, Wolff RA, Kaseb AO, et al. HER2/neudirected therapy for biliary tract cancer. J Hematol Oncol. 2015; 8:58.

17. Valle J, Wasan H, Palmer DH, Cunningham D, Anthoney A, Maraveyas A, Madhusudan S, Iveson T, Hughes S, Pereira SP, Roughton M, Bridgewater J, Investigators ABCT. Cisplatin plus gemcitabine versus gemcitabine for biliary tract cancer. N Engl J Med. 2010; 362:1273-1281.

18. Nam HJ, Ching KA, Kan J, Kim HP, Han SW, Im SA, Kim TY, Christensen JG, Oh DY, Bang YJ. Evaluation of the antitumor effects and mechanisms of PF00299804, a pan-HER inhibitor, alone or in combination with chemotherapy or targeted agents in gastric cancer. Mol Cancer Ther. 2012; 11:439-451.

19. Kim JW, Kim HP, Im SA, Kang S, Hur HS, Yoon YK, Oh DY, Kim JH, Lee DS, Kim TY, Bang YJ. The growth inhibitory effect of lapatinib, a dual inhibitor of EGFR and HER2 tyrosine kinase, in gastric cancer cell lines. Cancer Lett. 2008; 272:296-306.

20. Gelmon KA, Boyle FM, Kaufman B, Huntsman DG, Manikhas A, Di Leo A, Martin M, Schwartzberg LS, Lemieux J, Aparicio S, Shepherd LE, Dent S, Ellard SL, et al. Lapatinib or Trastuzumab Plus Taxane Therapy for Human Epidermal Growth Factor Receptor 2-Positive Advanced Breast Cancer: Final Results of NCIC CTG MA.31. J Clin Oncol. 2015; 33:1574-83.

21. Pivot X, Manikhas A, Żurawski B, Chmielowska E, Karaszewska B, Allerton R, Chan S, Fabi A, Bidoli P, Gori S, Ciruelos E, Dank M, Hornyak L, et al. CEREBEL (EGF111438): A Phase III, Randomized, Open-Label Study of Lapatinib Plus Capecitabine Versus Trastuzumab Plus Capecitabine in Patients With Human Epidermal Growth Factor Receptor 2-Positive Metastatic Breast Cancer. J Clin Oncol. 2015; 33:1564-73.

22. Okusaka T, Ishii H, Funakoshi A, Yamao K, Ohkawa S, Saito S, Saito H, Tsuyuguchi T. Phase II study of singleagent gemcitabine in patients with advanced biliary tract cancer. Cancer Chemother Pharmacol. 2006; 57:647-53.

23. Okusaka T, Nakachi K, Fukutomi A, Mizuno N, Ohkawa S, Funakoshi A, Nagino M, Kondo S, Nagaoka S, Funai J, Koshiji M, Nambu Y, Furuse J, et al. Gemcitabine alone or in combination with cisplatin in patients with biliary tract cancer: a comparative multicentre study in Japan. Br J Cancer. 2010; 103:469-74.

24. Ong CK, Subimerb C, Pairojkul C, Wongkham S, Cutcutache I, Yu W, McPherson JR, Allen GE, Ng CC, Wong BH, Myint SS, Rajasegaran V, Heng HL, et al. Exome sequencing of liver fluke-associated cholangiocarcinoma. Nat Genet. 2012; 44:690-693.

25. Jiao Y, Pawlik TM, Anders RA, Selaru FM, Streppel MM, Lucas DJ, Niknafs N, Guthrie VB, Maitra A, Argani P, Offerhaus GJ, Roa JC, Roberts LR, et al. Exome sequencing identifies frequent inactivating mutations in BAP1, ARID1A and PBRM1 in intrahepatic cholangiocarcinomas. Nat Genet. 2013; 5:1470-1473.

26. Chan-On W, Nairismagi ML, Ong CK, Lim WK, Dima S, Pairojkul C, Lim KH, McPherson JR, Cutcutache I, Heng HL, Ooi L, Chung A, Chow P, et al. Exome sequencing identifies distinct mutational patterns in liver fluke-related and non-infection-related bile duct cancers. Nat Genet. 2013; 45:1474-1478.

27. Aishima SI, Taguchi KI, Sugimachi K, Shimada M, Sugimachi K, Tsuneyoshi M. c-erbB-2 and c-Met expression relates to cholangiocarcinogenesis and progression of intrahepatic cholangiocarcinoma. Histopathology. 2002; 40:269-278.

28. Yoshikawa D, Ojima H, Iwasaki M, Hiraoka N, Kosuge T, Kasai S, Hirohashi S, Shibata T. Clinicopathological and prognostic significance of EGFR, VEGF, and HER2 expression in cholangiocarcinoma. Br J Cancer. 2008; 98:418-425.

29. Lee HJ, Chung JY, Hewitt SM, Yu E, Hong SM. HER3 overexpression is a prognostic indicator of extrahepatic cholangiocarcinoma. Virchows Arch. 2012; 461:521-530.

30. Andersen JB, Spee B, Blechacz BR, Avital I, Komuta M, Barbour A, Conner EA, Gillen MC, Roskams T, Roberts LR, Factor VM, Thorgeirsson SS. Genomic and genetic characterization of cholangiocarcinoma identifies therapeutic targets for tyrosine kinase inhibitors. Gastroenterology. 2012; 142:1021-1031 e1015.

31. Ku JL, Yoon KA, Kim IJ, Kim WH, Jang JY, Suh KS, Kim SW, Park YH, Hwang JH, Yoon YB, Park JG. Establishment and characterisation of six human biliary tract cancer cell lines. Br J Cancer. 2002; 87:187-193.

32. Eisenhauer EA, Therasse P, Bogaerts J, Schwartz LH, Sargent D, Ford R, Dancey J, Arbuck S, Gwyther S, Mooney M, Rubinstein L, Shankar L, Dodd L, et al. New response evaluation criteria in solid tumours: revised RECIST guideline (version 1.1). Eur J Cancer. 2009; 45:228-247.

33. Ukita Y, Kato M, Terada T. Gene amplification and mRNA and protein overexpression of c-erbB-2 (HER-2/neu) in human intrahepatic cholangiocarcinoma as detected by fluorescence in situ hybridization, in situ hybridization, and immunohistochemistry. J Hepatol. 2002; 36:780-785.

34. Kim HJ, Yoo TW, Park DI, Park JH, Cho YK, Sohn CI, Jeon WK, Kim BI, Kim MK, Chae SW, Sohn JH. Gene 
amplification and protein overexpression of HER-2/ neu in human extrahepatic cholangiocarcinoma as detected by chromogenic in situ hybridization and immunohistochemistry: its prognostic implication in nodepositive patients. Ann Oncol. 2007; 18:892-897.

35. Wolff AC, Hammond ME, Hicks DG, Dowsett M, McShane LM, Allison KH, Allred DC, Bartlett JM, Bilous M, Fitzgibbons P, Hanna W, Jenkins RB, Mangu $\mathrm{PB}$, et al. Recommendations for human epidermal growth factor receptor 2 testing in breast cancer: American Society of Clinical Oncology/College of American Pathologists clinical practice guideline update. J Clin Oncol. 2013; 31:3997-4013.

36. Chou TC, Talalay P. Quantitative analysis of dose-effect relationships: the combined effects of multiple drugs or enzyme inhibitors. Adv Enzyme Regul. 1984; 22:27-55. 